\title{
Resectable Pancreatic Carcinoma
}

National Cancer Institute

\section{Source}

National Cancer Institute. Resectable Pancreatic Carcinoma. NCI Thesaurus. Code C5099.

Carcinoma of the pancreas amenable to surgical removal. 